\title{
EDUCAÇÃO DOS IMIGRANTES JAPONESES EM DOURADOS / MS: DOS VALORES FAMILIARES À CONCEPÇÃO ESCOLAR NA CULTURA NIPO-BRASILEIRA
}

\author{
Vivian Iwamoto ${ }^{\mathrm{D} 1}$ e Joice Camila dos Santos Kochi ${ }^{\text {(D) } 2}$
}

\section{Resumo}

As diversas imigrações tuteladas ao Brasil tiveram importância econômica e social para a construção da nação. Questões essas que igualmente ocorreram com a imigração japonesa. Nesse sentido, este artigo teve como objetivo compreender as figurações da educação formal e informal da comunidade nipobrasileira em Dourados, Mato Grosso do Sul, no curso do processo civilizador. Por meio de fontes documentais e orais, a História Oral corroborou no processo metodológico da investigação acerca das redes de interdependências entre brasileiros e japoneses. Percebeu-se que os valores familiares da educação informal, reforçados na escola de uma educação formal, consolidou um habitus fundamental para a permanência do grupo na região estudada. Imersos nesse processo, os imigrantes japoneses acabaram regulando e autorregulando o comportamento, enquanto "segunda natureza". Além disso, os participantes da pesquisa demonstraram o sucesso obtido pela escolha de terem vindo ao Brasil, evidenciando a persistência nipônica fundamental à formação de sua personalidade, empreendido na força do trabalho árduo. Suportar com paciência e superar nos esforços, mais do que sofrimento e dificuldades transpassados, a autodisciplina e a dedicação empreendidos na jornada, resultaram na conquista e no sucesso de viver em um país totalmente diferente do mundo conservado em suas memórias.

Palavras-chave: Imigração Japonesa; História Oral; Processo Civilizador.

\section{JAPANESE IMMIGRANTS' EDUCATION IN DOURADOS / MS: FROM FAMILY VALUES TO SCHOOL CONCEPT IN NIPO-BRAZILIAN CULTURE}

\section{Abstract}

The various immigrants tutelaged by Brazil had their economic and social importance for the construction of the nation. These issues have also occurred with Japanese immigration. In this sense, this article aimed to understand the figuration of formal and informal education of the Japanese-Brazilian community in Dourados, Mato Grosso do Sul, in the course of the civilizing process. Through documentary and oral sources, Oral History corroborated the methodological

\footnotetext{
${ }^{1}$ Doutoranda em Educação pela Universidade de São Paulo (USP). Coordenadora e Docente no Curso de Educação Física do Centro Universitário da Grande Dourados (UNIGRAN EAD). E-mail: vivianiwamoto@usp.br

${ }_{2}^{2}$ Mestre em Educação pela Universidade Federal da Grande Dourados (UFGD). Professora efetiva na rede municipal de Dourados-MS. E-mail: joice.kochi@gmail.com
}

Perspectivas em Diálogo, Naviraí, v. 08, n. 17, p. 193-214, maio/ago. 2021. 
process of the investigation about the interdependence networks between Brazilians and Japanese. It was noticed that the family values of informal education, reinforced in a formal education school, consolidated a fundamental habitus for the group to remain in the studied region. Immersed in this process, Japanese immigrants ended up regulating and self-regulating behavior, as "second nature". In addition, participants demonstrated the success obtained by choosing to come to Brazil, showing the Japanese persistence fundamental to the formation of their personality, undertaken in the force of hard work. Withstand with patience and overcome in efforts, more than suffering and difficulties passed through, the self-discipline and dedication undertaken in the journey, resulted in the conquest and success of living in a country totally different from the world preserved in its memories.

Keywords: Japanese Immigration; Oral History; Civilizing Process.

\section{Introdução}

Em junho de 2020 comemorou-se os 112 anos da Imigração Japonesa no Brasil. Depois de firmado o Tratado de Amizade, Comércio e Navegação entre o Brasil e Japão em 1895, foi concretizada a chegada dos primeiros 781 imigrantes japoneses no porto de Santos-SP no navio Kasato Maru em 1908. Com o número aumentando a cada ano, até o final do século XX somaram-se mais de 1.200.000 japoneses e descendentes (SAKURAI, 2000). Com diversos interesses de ambos os países, a imigração japonesa no Brasil teve uma característica de "imigração tutelada", uma "[...] imigração dirigida, subsidiada e estimulada por ambas as pontas da corrente: o Japão e o Brasil. Cada país tem os seus interesses próprios, que se coadunam com o momento histórico em que se desenrola" (SAKURAI, 2000, p. 3).

Já a vinda dos imigrantes/migrantes para Mato Grosso do Sul1 teve início ainda na primeira década do século $X X$ e a sua história, conforme Edna Mitsue Inagaki (2008, p. 32), "[...] está ligada à construção da Estrada de Ferro Noroeste do Brasil, que ligava Bauru a Porto Esperança, no antigo Mato Grosso, próximo a Corumbá". Essa imigração se dá de forma secundária, pois os destinos primordiais foram os cafezais do interior do estado de São Paulo. Assim, no ano de 1909, esses imigrantes, ao serem atraídos pela remuneração mais compensadora da construção da Estrada de Ferro Noroeste do Brasil (NOB) do que nas fazendas cafeeiras, resolvem se encaminhar para a região centro-oeste do país (KUBOTA, 2008).

De fato, a derrota do Japão na Segunda Guerra Mundial fez com que os japoneses que viviam em São Paulo reorganizassem suas vidas, favorecendo os que muitos sem perspectivas de retorno ao seu país de origem decidissem por uma mudança em direção ao interior do Brasil e, por isso, grande parte desse grupo veio para a região de Dourados-MS, na busca de melhoria de vida. Por

\footnotetext{
${ }^{1}$ Embora a divisão do estado entre Mato Grosso e Mato Grosso do Sul tenha ocorrido em 1977,
} manteremos ao longo do trabalho a alusão sobre Mato Grosso do Sul.

Perspectivas em Diálogo, Naviraí, v. 08, n. 17, p. 193-214, maio/ago. 2021. 
isso, para compreender a vinda desses imigrantes japoneses para Mato Grosso do Sul, especificamente em Dourados, utilizamos como aporte teórico as contribuições de Norbert Elias (1993; 1994; 2011; 2014), na intenção de entender como foram se estabelecendo na cidade e quais valores preconizaram em sua educação familiar e, consequentemente, em sua educação escolarizada.

Sendo assim, este trabalho parte da reflexão de duas pesquisas de mestrado1 concluído, nas quais utilizaram-se como metodologia as contribuições da História Oral (ARBERTI, 2008; MEIHY, 1996; POLLAK, 1989; PORTELLI, 1997) valorizando a memória e o relato de entrevistadas/os, além de fontes documentais (lista de associados, atas, registro de fundação, regimento interno), tanto da Escola Modelo de Língua Japonesa, quanto da Associação Cultural Nipo-Brasileira de Dourados e somando com os referenciais bibliográficos da cultura japonesa (BENEDICT, 1972; DEMARTINI, 2000; 2004; KUBOTA, 2008; MORALES, 2008; SAKURAI, 2000; 2014; SETOGUTI, 2008). Em suma, as/os entrevistadas/os são imigrantes japoneses da primeira geração, nascidas/os entre 1935 a 1940 no Japão, duas mulheres que fizeram parte da constituição da escola japonesa na cidade e dois homens membros do clube nipônico, entre os quais alguns se conhecem, mas não possuem parentesco entre si e, atualmente, moram na região da Grande Dourados, Mato Grosso do Sul.

As entrevistas com questões abertas foram realizadas entre os anos 2014 e 2017, nas casas dos participantes, previamente cientes dos riscos e benefícios da pesquisa e acordados com o Termo de Consentimento Livre e Esclarecido, o qual foi possível gravar o áudio de todo o processo e acompanhar os ditos, não ditos e os entreditos dos participantes. A maioria delas foram realizadas na língua japonesa e realizada a transcrição, a transliteração e a tradução ao português. José Carlos S. B. Meihy (1996) explica que os procedimentos são planejados e seguem um rigor de organização que cumpre alguns passos como: a) elaboração de um projeto; b) definição do grupo de pessoas ou colônia; c) condução das gravações; d) transcrição; e) conferência do depoimento; f) autorização inicial e final para o uso; g) arquivamento; h) publicação dos resultados, voltando ao grupo que o gerou. Respeitou-se todas as etapas, uma vez que a História Oral, mais do que sinônimo de entrevistas, é regida pelos fundamentos de estar apto a ouvir, gravar, registrar, transcrever e discutir as memórias construídas pelos participantes, com o olhar atento para suas histórias de vidas nas minúcias de suas expressões e no tempo/espaço de sua elaboração.

Para tanto, podemos apresentar primeiramente a professora Satoko, nascida em 1936 - 79 anos na data da entrevista. Chegou no Brasil em 1956 com 19 anos de idade. Formada em Koko (equivalente ao ensino médio do Brasil), imigrou no Brasil com sua família, a qual era composta por: pai, mãe,

\footnotetext{
${ }^{1}$ Dissertação Mestrado em Educação intitulado "Educação e civilidade nas memórias de infância de imigrantes japoneses" defendido pela autora Vivian Iwamoto no Programa de Pós-Graduação em Educação pela Universidade Federal da Grande Dourados (UFGD) em 2016 e Dissertação de Mestrado em Educação intitulado '"Escola Modelo de Língua Japonesa de Dourados': Movimentos, Histórias e Memórias de mulheres", defendido pela autora Joice Camila do Santos Kochi pelo mesmo programa de pós-graduação em 2017.
} 
um irmão mais velho, ela e dois irmãos mais novos. Inicialmente, a família imigrou no interior do estado do Paraná, porém outras oportunidades surgiram nos anos de 1960, fazendo com que migrassem para a região de Dourados. Timidamente, ainda jovem, começou a participar nas festividades da associação de japoneses da região; após se casar decidiu cuidar das crianças da vizinhança, ao mesmo tempo em que recebia visita em casa. Assim inicia o movimento da educação étnica, no início com intuito de ensinar somente para o seu filho a sua língua materna.

A segunda entrevistada é a sra. Yasuko, nascida em 1935, 80 anos, imigrou para o Brasil em 1956 aos 20 anos de idade. Sua vida no Japão sempre foi na área rural, sendo assim não pôde estudar até o Koko, se formando somente no Chugakko - "primeiro ciclo do segundo grau em três anos" (equivalente aos anos finais do ensino fundamental do Brasil). Ela menciona diversas vezes na entrevista sobre a sua escolaridade, quando relata sobre os convites de dar aulas nas associações, lamenta-se por não ter conseguido estudar no Japão até o Koko, pois precisava trabalhar na lavoura para ajudar a sua família.

Em seguida, Shiro Taniguchi, 75 anos, nascido em 1940, na província de Wakayama Ken, na cidade Hidaka Gun, veio ao Brasil em 1953. Dentre cinco filhos, é o segundo mais velho. Veio ao Brasil com os pais e se casou com Midori Taniguchi; Teve três filhos, duas mulheres e um homem; Estudou até o sexto ano do Shogakko (ensino primário, anos iniciais do ensino fundamental do Brasil) e atualmente continua trabalhando em suas terras na plantação de soja e trigo.

Por fim, Yuji Nakano, 75 anos, nascido em 1940, na província de Hokkaido, na cidade Kitami Shi, veio ao Brasil em 1956. O senhor Nakano, dentre oito filhos, sendo quatro mulheres e quatro homens, é o quinto mais velho. Vieram todos ao Brasil; Em sua infância frequentou até o segundo ano do Chugakko (ensino secundário inferior, anos finais do ensino fundamental do Brasil); Atualmente é aposentado e casado com Terumi Konaka Nakano, possuindo quatro filhos, três mulheres e um homem.

Conforme as experiências desses/as entrevistados/as e o cruzamento com as fontes documentais, não se pode negar que os movimentos internos do Japão, antes, durante e após a Segunda Guerra Mundial foram contextos incorporados na educação inicial destes. As situações vividas, que marcaram a vida pessoal e familiar dos grupos que emigraram para outras terras, certamente são evidentes na forma como compreendem a cultura e a educação de seu país de origem e como se relacionam com o país de recepção. Para tanto, tentaremos compreender essas relações a seguir.

\section{A infância e a educação da criança: valores da cultura japonesa}

Em uma sociedade composta por adultos e crianças no processo constante de formação e trocas entre grupos sociais diversos, ao pensar a infância e sua educação, consideramos os grupos compostos por diferentes gerações como 
parte da construção social, histórica e cultural das configurações específicas que as pessoas formam umas com as outras. Do ponto de vista de Elias (2014, p. 144), "o conceito de configuração chama a atenção para a interdependência das pessoas". Sem pensar indivíduo e sociedade como entidades antagônicas, nem apenas aglomeração de agentes individuais, suas ações são interdependentes e relativas uns aos outros. Continua, "realmente aí se encontra todo o segredo das configurações sociais, sua dinâmica irresistível, suas regularidades estruturais, o caráter de seu processo e de seu desenvolvimento, e é esse o segredo da sociogênese e da dinâmica das relações" (ELIAS, 1993, p. 140). Isto é, o resultado dos entrelaçamentos de interesses e intenções das relações entre as pessoas.

Dessa maneira, o entendimento sobre a infância passa a ser parte da história da sociedade, em um processo civilizador. Desse modo, para compreender a infância precisamos apreender a configuração social a qual ela se insere, ou seja, seus modos de comportamentos que a constitui e estão em constantes mudanças. Por conseguinte, nessas relações estabelecidas entre adultos e crianças, inferimos, concordando com Elias (2014, p. 15), que "estas pessoas constituem teias de interdependências ou configurações de muitos tipos, tais como famílias, escolas, cidades, estratos sociais ou estados". Todos esses grupos organizados a seu modo participam da formação do indivíduo, uma vez que somos seres humanos entre outros seres humanos em uma rede de indivíduos socialmente orientados e as crianças também fazem parte disso.

Assim, no curso do processo civilizador - que se caracteriza por extrair dos indivíduos sua parcela de rudeza e de grosseria -, temos um caminho de aprendizagem social e de transformação do padrão de comportamento de um habitus social, a que Norbert Elias (1994) chama de "segunda natureza", uma forma de internalizar os padrões e costumes em forma habitual. As configurações geracionais e suas trocas de valores, não necessariamente uma se sobrepõe à outra, mas mutuamente possuem saberes específicos e fundamentais à sua existência. Nesse sentido, segundo Elias (1994, p. 8), os "padrões sociais de autorregulação que o indivíduo tem que desenvolver dentro de si, ao crescer e se transformar num indivíduo único, é específico em cada geração e, por conseguinte, num sentido mais amplo, específico de cada sociedade".

Podemos dizer, então, que a criança se insere em uma configuração social já existente anteriormente a ela e neste espaço social de inúmeras redes de interdependência consegue avançar em seu processo educativo. No que diz respeito a isso, para Elias (1994, p. 27),

Somente na companhia de outras pessoas mais velhas é que, pouco a pouco, desenvolve um tipo específico de sagacidade e controle dos instintos. E a língua que aprende, o padrão de controle instintivo e a composição adulta que nele se desenvolve, tudo isso depende da estrutura do grupo em que ela cresce e, por fim, de sua posição nesse grupo e do processo formador que ela acarreta. 
Nesse contexto, as sociedades atuais de maior complexidade são necessariamente mais organizadas e "pacificadas", exigindo de cada indivíduo um maior grau de autocontrole dentro do movimento civilizatório. Um processo de convivência social caracterizado pelo diálogo e pela polidez, de controle e autocontrole dos instintos e das emoções em uma sociedade mais humanizada em certa direção, determina que

O processo civilizador pode, por conseguinte, ser percebido também como um processo de educação das vontades, dos costumes e dos comportamentos, cujo intuito foi sempre tornar o homem mais humano, mais próximo possível de uma convivência social e mais afastado da barbárie e das suas características mais primitivas (GEBARA E SARAT, 2009, p. 12).

Enquanto sujeitos sociais, as crianças e suas infâncias, de um modo geral, possuem multiplicidade de distinção referendada nas relações de classes sociais, gêneros, etnias, contextos geográficos e culturais, que as tornam concretas e presentes socialmente. Em vista disso, consentimos com a ideia de que "não existe uma infância, mas várias, cada uma com seus pontos de referência particulares, que não podem ser plenamente compartilhados por outras infâncias" (NASCIMENTO, 2011, p. 41-43). Portanto, a descrição geral sobre o habitus japonês apresenta-se em uma perspectiva de organização social que possibilitou entender a origem das peculiaridades culturais prezada em sua formação. Assim sendo,

O compromisso existe em todos os níveis da sociedade japonesa e em todas as suas instituições; a educação é vista como chave do desenvolvimento industrial, da coesão nacional, da estatura política internacional, do desenvolvimento pessoal, da construção do caráter moral, da continuidade cultural e da criação e manutenção dos relacionamentos interpessoais (WHITE, 1988, p. 21).

A autora demonstra que, consensualmente, a educação é necessária para autonomia do "ser individual" e, ao mesmo tempo, para a confirmação enquanto membro de um grupo. O "bom-senso japonês", de uma educação moral não dicotomizada em "social" e "pessoal", o que incluem: respeito pela liberdade do outro; suportar dificuldades; persistir com paciência; ouvir a opinião dos outros; admitir abertamente os próprios erros e culpas; viver uma vida de moderação, com prudência e ordenada. Além disso, não é considerada uma perspectiva imposta, mas sim estabelecida com o consentimento do indivíduo, em um propósito de união e harmonia do grupo, funcionando como pauta da educação nipônica (WHITE, 1988). O mesmo é ratificado por Kishimoto (1995, p. 33), "valores como cooperação, respeito pela harmonia do grupo e cordialidade são inerentes aos japoneses e fazem parte de sua cultura".

Em outras palavras, para além da matemática, língua japonesa, ciências ou estudos sociais, os modos de comportamento e o conjunto de etiqueta social, ainda hoje, valoriza-se muito a concordância com o propósito de união, que "[...] 
constitui a pauta principal da educação nipônica" (WHITE, 1988, p. 36), aspecto visto como algo singularmente japonês. Talvez seja nisso que o valor educacional se concentra, da forma como afirma Camacho (2012, p. 94), "the school education, view as a value of first greatness in Japan, is considered strategic in the service of national and personal economical interests. The culture is assigned of the input of that value"1. Por isso, pais, professores e chefes, todos estão envolvidos na formação do indivíduo, enquanto composição do grupo.

A etiqueta social de uma ética que depende de cada um, normalmente realizado sem descontentamento, pode-se causar constrangimento e vergonha caso não se cumpra suas normas. Como confirma Benedict (1972, p. 190), "a vergonha, dizem eles, é a raiz da virtude. Quem é sensível a ela cumprirá todas as regras de boa conduta". Tal emoção também foi objeto de investigação de Goudsblom (2009, p. 55). Conforme o autor, a vergonha é

[...] derivada do medo; medo da perda dos dois mais preciosos reconhecimentos da vida social, o respeito e a afeição. [...] Mais que qualquer outra emoção a vergonha é uma emoção exclusivamente social. [...] Ao fazer algo inconveniente colocamos em risco nossa posição social, sentimos que merecemos a humilhação, ou mesmo ser excluídos, e mostramos como nos sentimos pequenos e invisíveis.

Assim, o cultivo do ato de se envergonhar pode ser usado como mecanismo de controle social. Tal processo de formação da consciência de acordo com as normas impostas pelos grupos de poder e distinção, envergonhar-se publicamente pode levar à humilhação, expulsão, aniquilação ou suicídio. Portanto, cultivar a possibilidade de seguir normas e regras que não leve a esses constrangimentos, torna a educação mais contida e desafia o indivíduo a se autocontrolar.

Nesse sentido, "para Elias, o autocontrole é o código social de conduta, gravado tão fortemente no indivíduo, que torna-se um elemento constituinte do próprio, agindo até quando o indivíduo encontra-se sozinho" (BRANDÃO, 2009, p. 83).

O medo de transgredir e a vergonha do fracasso tornam-se uma forma de disciplinar o convívio coletivo de não se expor. Dentro da educação do indivíduo, "[...] submete-se ele, portanto, a um autotreinamento a fim de eliminar a autocensura da vergonha (haji)" (BENEDICT, 1972, p. 211). Nessa leitura, a formalização dos costumes e a disciplinarização das pessoas correspondem a uma concepção de uma personalidade autorregulada, de modo que, o que era imposto conscientemente por outras pessoas por razões sociais, passa a ser um

1"A educação escolar, vista como um valor de primeira grandeza no Japão, é considerada estratégica no atendimento de interesses econômicos nacionais e pessoais. A cultura se incumbe da internalização desse valor" (tradução livre). 
hábito, um autocontrole automático ou o que Elias (2011) chama de "segunda natureza"1.

O nível habitual de autocontrole consolidado no convívio social permite certo relaxamento dos costumes, que na verdade, "o que se observa é uma relaxação dentro do contexto de um padrão já firmemente radicado" (ELIAS, 2011 , p. 139). Sendo assim, é possível dizer que, nesse caso, a menor pressão social externa se torna maior pressão interna do indivíduo. A autorregulação da conduta e dos sentimentos permanece ligada à opinião normativa do grupo de modo intrínseco, quer dizer, a crescente interdependência de indivíduos dentro de uma figuração social, influi no contínuo fluxo de trocas de diferentes ordens.

Nessas circunstâncias da relação com o outro que o processo educativo pode contemplar a aprendizagem das normas como forma de participar e ser aceito socialmente, evitando o sentimento de vergonha ou modificando os estigmas impostos. O processo de aprendizagem com o outro passa a ser internalizado como forma de autorregulação, pois, "cada vez mais, o medo dos socialmente superiores e, de forma mais geral, o medo de transgredir as proibições sociais tomou a forma de um medo interior, a vergonha" (WOUTERS, 2009, p. 99).

Percebemos, então, que diferentemente do ocidente, este baseado nos valores do Judaísmo e Cristianismo, os quais a importância se vincula na supremacia do bem e do mal e, por conseguinte, na ênfase da culpa, no Japão as pessoas são movidas pela cultura da vergonha e do comprometimento das relações entre seus pares.

Igualmente, o que para os ocidentais a autodisciplina possui uma conotação negativa, ligada aos sacrifícios, renúncias e frustrações, para os japoneses ela possibilita a capacidade de controle e respaldo à conduta, intimamente ligada à responsabilidade. Em síntese, enquanto os ocidentais entendem a disciplina (obediência) como necessária, mas potencialmente negadora do ser, os japoneses entendem-na plenamente assumida como refinadora e constituinte do ser.

Tais habilidades e padrões de comportamentos estabelecidos na cultura japonesa tendem a se vincular à educação e à formação da criança em todos os espaços sociais da qual ela faz parte. Esses comportamentos se disseminaram e passaram a fazer parte das gerações seguintes. Tão logo, são esses os aspectos investigados em nossa pesquisa constituinte da educação familiar japonesa de gerações que vieram para o Brasil.

\footnotetext{
${ }^{1}$ Exemplos de costumes da corte francesa do que era permitido e que passou a ser proibido são citados por Elias (2011). Demonstra que as atividades relacionadas à parte "animal" ou "primeira natureza" dos seres humanos, tornaram-se privadas em relação ao restante da vida social. As proibições sociais se tornaram forma de autocoação, uma vez que "boas maneiras" não são naturais. "Na medida em que essas coações tornaram-se auto-coações que funcionam de forma mais ou menos automática, esses padrões de comportamento tornaram-se 'segunda natureza'" (WOUTERS, 2009, p. 100).
} 


\section{Escola japonesa: o legado da família}

A tradição cultural japonesa possui influências do bushido ${ }^{1}$ que funciona como uma "bússola da conduta". Guiando a educação nipônica, "even after the decline of the samurai class, from 1872, this spirit continued on the mentality and on the Japanese way of life and it is deeply present on the behavior of these immigrants and their descendents [...]"2 (OCADA, 2012, p. 119). Alguns dos valores herdados pelos samurais (sobriedade, disciplina e lealdade) ainda perpassam pela vida de seus descendentes, mesmo que a classe guerreira tenha sido obliterada, conservam em suas memórias e nas relações interpessoais do cotidiano. Ligado a isso, não há como dissociar a educação familiar da educação escolar dos japoneses. A preocupação com a instrução escolar está intimamente ligada aos valores adotados nos costumes (IWAMOTO, 2016).

Nesse sentido, um aspecto importante no processo imigratório foi a instauração de escolas japonesas no Brasil, que marcou a existência social do grupo e viabilizou sua pertença étnica mesmo em um país estrangeiro.

Logo ao chegar, e em decorrência também da inexistência de escolas em grande parte dos lugares para os quais se dirigiam, criavam escolas, geralmente segundo os padrões do sistema educacional japonês, embora procurassem respeitar a legislação nacional, restritivas às escolas "étnicas" desde a Primeira Guerra Mundial. [...] Não parecia haver um rompimento entre a escola e as famílias, mas, ao contrário, as famílias não só construíram e mantinham as escolas, como estavam presentes na orientação e controle de seu funcionamento (DEMARTINI, 2004, p. 219).

Mesmo que não fossem homogêneas e houvesse pressões nacionalistas, principalmente na década de 1930 , as escolas foram construídas dentro das possibilidades dos grupos. A preocupação era suprir a educação dos filhos, promover cooperação entre os membros, manter a língua, os costumes e a tradição, tendo em vista que "a formação de uma concentração ou colônia de japoneses, dentro de dois ou três anos constrói-se uma escola. Um dos primeiros e principais objetivos da fundação de uma associação de japoneses é precisamente a educação dos filhos de imigrantes" (VÁRIOS AUTORES, 1992, p. 123).

Na análise de Demartini (2000), não havia um padrão único na constituição das escolas, mas foram originadas a partir de quatro ocasiões: escolas surgidas da união de famílias - pelo interesse dos pais em proporcionar certo grau de escolaridade aos descendentes; escolas fundadas por recursos particulares - para atender a demanda da comunidade; escolas criadas pelas companhias de imigração; e escolas criadas por entidades religiosas. A estratégia de construir escolas fazia parte do processo de estabelecimento dos

\footnotetext{
${ }^{1}$ Bushido, código de ética dos samurais (da classe guerreira japonesa) (WAKISAKA, 2003).

2 "Mesmo após o declínio da classe samurai, a partir de 1872, este espírito continuou fortemente presente na mentalidade e no modo de vida dos japoneses, marcando profundamente o comportamento desses imigrantes e de seus descendentes [...]" (tradução livre).
} 
imigrantes, uma vez que as escolas "tinha de educá-los de modo a não terem dificuldades na vida, não ficarem atrás dos outros e, mais ainda, preservarem o espírito e as virtudes do súdito japonês para não se envergonharem quando retornassem à terra natal" (VÁRIOS AUTORES, 1992, p. 132).

Um processo conflituoso se expressava no dilema entre investir na educação japonesa ou na educação brasileira, isto é, paradoxos da imigração que são estrangeiros no país em que se alocaram e também em seu país de origem, quando regressam. Permanentemente com a ideia de retorno, caso voltassem ao Japão, os filhos teriam de saber falar e ler, estabelecendo um mínimo de comunicação. Se houvesse tal defasagem, seria vergonhoso para a família. E, caso permanecessem no Brasil, teriam que investir no sustento e na possibilidade de se ascenderem socialmente. As balanças de poder presentes nessas relações ambíguas de ser imigrante.

Situação que, a partir dos anos 1930, com um governo centralizador e nacionalista, estabeleceram-se maiores regulações aos estrangeiros e seus descendentes. A vigilância em relação à educação afetou as escolas nipônicas e medidas foram exigidas:

1) proibição do ensino de língua estrangeira a crianças de menos de dez anos de idade; 2 ) o professor de língua estrangeira deve ser aprovado no exame de habilitação para a matéria; 3) os livros de ensino de língua estrangeira devem ser previamente aprovados pelas autoridades de fiscalização; 4) proíbe-se o uso de livros didáticos prejudiciais à formação do espírito nacional brasileiro (VÁRIOS AUTORES, 1992, p. 128).

Diante desse contexto político, era explícito no decreto-lei no 406, de 4 de Maio de 1938 as exigências em relação ao estrangeiro e as normativas em relação aos seus costumes e o uso da língua.

Art. 85. Em todas as escolas rurais do pais, o ensino de qualquer matéria será ministrada em português, sem prejuízo do eventual emprego do método direto no ensino das línguas vivas.

$\S 1^{\circ}$ As escolas a que se refere este artigo serão sempre regidas por brasileiros natos.

$\S 2^{\circ}$ Nelas não se ensinará idioma estrangeiro a menores de quatorze (14) anos.

$\S 3^{\circ}$ Os livros destinados ao ensino primário serão exclusivamente escritos em línguas portuguesa.

$\S 4^{\circ}$ Nos programas do curso primário e secundário é obrigatório o ensino da história e da geografia do Brasil.

$\S 5^{\circ}$ Nas escolas para estrangeiros adultos serão ensinadas noções sobre as instituições políticas do país.

Art. 86. Nas zonas rurais do país não será permitida a publicação de livros, revistas ou jornais em línguas estrangeira, sem permissão do Conselho de Imigração e Colonização. 
Art. 87. A publicação de quaisquer livros, folhetos, revistas, jornais e boletins em língua estrangeira fica sujeita à autorização e registro prévio no Ministério da Justiça.

Contudo, na intenção de resistir, pequenos grupos ainda eram formados, às escondidas, em casas particulares, como forma de subversão ao governo e pela necessidade educativa de preservar a língua e a cultura. As escolas japonesas foram reabertas apenas na década de 1950, principalmente em 1953, quando a imigração japonesa se reinicia após a Segunda Guerra Mundial.

No caso do estado de Mato Grosso do Sul, em 1983, o Departamento de Difusão da Língua Japonesa foi criado pela associação Cultural Nipo-Brasileira Sul-Mato-Grossense, instituindo em 1989 a fundação da Escola Modelo (escola japonesa) na cidade de Dourados. Tal escola continua em funcionamento nos dias atuais e propicia estratégias para uma educação escolar como forma de extensão da educação familiar nos moldes dos valores japoneses. Tal ênfase indica uma dinâmica social do grupo na manutenção tanto de valores morais de comportamento, quanto na busca de certa estabilidade econômica e ascensão social. À vista disso, no intuito de apresentar sua trajetória e suas concepções sobre a temática, prosseguiremos na discussão sobre a escola japonesa em Dourados-MS.

\section{Escola modelo de língua japonesa: ensino da língua e da cultura oriental}

Em fevereiro de 1990, a comunidade japonesa começa a frequentar a "Escola Modelo de Língua Japonesa de Dourados", agora resultado da unificação das Nihon Gakkou's da região. A busca e a valorização da educação japonesa se concentram nos "[...] atributos morais e comportamentais da criança enquanto aprende e desempenha" (WHITE, 1988, p. 42). Nesse contexto, podemos observar aspectos da preocupação com a educação moral desde a fundação da escola e de seus objetivos. No documento Princípios e Objetivos da "Escola Modelo de Língua Japonesa de Dourados" lemos:

- Ensinar a Língua Japonesa não somente aos descendentes japoneses, mas também a todas as pessoas que se interessarem;

- A meta educacional desta escola está baseada no método básico educacional, e na metodologia educacional do Centro de difusão de língua japonesa; de modo que as crianças sejam adaptadas nas condições de nossa região, obedecendo as necessidades e costumes e a fixação de um corpo discente adequado;

- Formar novos professores com os alunos capacitados que estudem nesta escola;

- Formar cidadãos com personalidade capaz de projetar suas capacidades com sociabilidade, cultura e saúde e

- Divulgar e transmitir a cultura japonesa (ESCOLA MODELO DE LÍNGUA JAPONESA DE DOURADOS, 1990). 
Ainda que a meta esteja baseada na metodologia do Centro de Difusão de Língua Japonesa (hoje CBLJ), a escola não deixou de pensar na condição regional, ao qual as crianças estão inseridas, valorizando a especificidade local. Do mesmo modo, ainda no documento, as metas apontam nessa direção:

- Criar através da língua Japonesa, cidadãos conscientes que tenham respeito humano, ampliar o ângulo da visão internacional, respeitando a tradição e a cultura de outros países;

- Alunos analíticos, interpretativos, com iniciativa própria;

- Alunos com personalidade forte e persistente e

- Alunos humanos e de coração próspero (ESCOLA MODELO DE LÍNGUA JAPONESA DE DOURADOS, 1990).

Nesse documento, vemos expressos os princípios, os objetivos e as metas que dirigem a cultura e permitem analisar nos pontos destacados a valorização da educação e do código moral para os alunos, como uma das ênfases educacionais da "Escola Modelo". Conforme White (1988, p. 79), para os japoneses, "[...] a escola é vista como um meio ambiente moral, o que também acontece com o ambiente de trabalho, local onde a virtude pessoal está ligada ao desempenho do indivíduo". Neste sentido, na sociedade nipônica praticamente não há distinção de moralidade social ou pessoal, portanto:

Zelo, esforço e abnegação devem ser combinados com alegria e sensibilidade em relação aos outros - tudo dentro do contexto de aprender a "amar nossa cidade natal e proteger o território, cultura e tradições da mãe pátria e [...] estar atento à nossa responsabilidade como japoneses (MINISTÉRIO DA EDUCAÇÃO, 1983 , p. 116, apud WHITE, 1988, p. 36).

Tal percepção da moralidade social está historicamente ligada à constituição do espaço educacional do Japão, pois a educação seria justamente para sustentar a moralidade tradicional da sociedade, constituindo a estrutura cultural do povo nipônico. Tal concepção pode ser percebida, também, na fala da sra. Satoko, quando o jovem japonês a procurou para desabafar sobre o comportamento das crianças nikkeis ${ }^{1}$ da cidade de Dourados, deixando evidente que estas não seguiam os padrões de comportamentos esperados para indivíduos que recebem uma educação japonesa.

Ele dizia, "eu acredito na importância da educação/ensino da língua japonesa. Cheguei aqui e vi o mau comportamento dos descendentes de imigrantes japoneses. Da vontade de não ver. Que tipo de comportamento é esse! Fico chateado. E ainda diz "eu sou japonês"... Não queria que muitos se denominassem assim, muito... [...]dizia que isso acontecia por não ter escola de língua japonesa (SATOKO, 2016).

${ }^{1}$ Significa descendência japonesa (WAKISAKA, 2003). 
Esse fragmento aponta a percepção de um recém-chegado e era preciso levar em conta que ele estava se referindo a uma segunda geração no Brasil, aos filhos dos imigrantes. Esperavam-se determinados comportamentos, que eram as marcas do modo de ser japonês. Na percepção do jovem japonês, as crianças nikkeis estavam fora do padrão social de sua cultura de origem, o Japão, embora as crianças observadas fossem brasileiras. E, no entanto, ele esperava destas crianças, a segunda geração, um comportamento construído a partir da educação que deveria ter sido ensinada pelos pais japoneses na construção do habitus ou da segunda natureza nipônica.

Desse modo, segundo o depoimento da sra. Satoko, o principal caminho de transmissão desses valores seria o ensino da língua. Considerando a língua como um dos principais elementos de vínculo entre os grupos sociais, como Elias (2001, p. 64) esclarece, "todo ser humano se torna vinculado aos outros desde a mais tenra idade aprendendo a usar, como meio de emitir e receber mensagens, um código de símbolos específicos do grupo, ou, em outras palavras, uma língua". Para esse autor, somente o grupo humano tem uma língua como meio de comunicação, como também a sua exigência de sentido, o qual podemos entender aqui como significado que transmite de forma subjacente os valores, cultura e hábitos.

Certamente, entre os humanos, padrões sonoros produzidos por uma pessoa podem ter um 'sentido' para outras. Mas só têm sentido - e porque - o emissor e o receptor aprenderam associar aos conjuntos específicos de padrões sonoros as mesmas imagens mnemônicas, ou em outras palavras, o mesmo sentido. Nesta forma, a mais elementar, de 'sentido', seu caráter social se mostra claramente (ELIAS, 2001, p. 64).

Nesse aspecto, a língua se apresenta como um elemento primordial da aprendizagem cultural, fazendo parte do legado de preservação histórica dos grupos, pois somente a partir de seus elementos as crianças se apropriam das referências que fazem parte do seu grupo social.

[...] o que decide qual língua será gradualmente depositada no aparelho de linguagem do indivíduo é a sociedade em que ele cresce. E os hábitos pessoais de fala, o estilo mais ou menos individual de discurso que o indivíduo pode ter quando adulto, são uma diferenciação no interior do meio linguístico em que ele cresce. São uma função de sua história individual dentro de sua sociedade e da história desta. [...] E a coisa não é muito diferente no que tange ao material efetivo que a linguagem procura expressar, o pensamento e o sentimento (ELIAS, 1994, p. 40).

Portanto, podemos dizer que foi em busca dessa educação moral e cultural, dos modos e comportamentos que se aprendem e se apropriam, por meio do ensino de língua de modo formalizado, que os/as imigrantes japoneses/as de Dourados e região se envolveram em um projeto de "Escola Modelo" defendendo essa premissa. Destacamos que a escola tinha um grande interesse e investia na 
formação de professores, desde os anos 1970, influenciando no sentido de valorizar a formação humanística por meio da língua e da cultura japonesa. As senhoras Satoko e Yasuko nos contam que todos os anos viajavam para São Paulo para receber uma formação específica de ensino da língua japonesa:

Em 1970, 78 mais ou menos. O/a professor/a de Dourados, ia direto para São Paulo, por questões particulares. E quando dava certo de participar, dizia que era muito boa (a formação), eu ouvia essas histórias. Eu não ia, não sabia nada disso. Então, em 1970 comecei ir (nas formações)... Mas era muito trabalhoso. Eu mesma tinha que pagar tudo, e.... (SATOKO, 2016).

As escolas japonesas eram mais um espaço social, de promoção da cultura japonesa, do que propriamente uma escola de idioma, já que a aquisição dessa língua, tinha como concepção que ela fosse interiorizada de forma natural, estando na perspectiva de Língua de Herança (MORALES, 2008). Assim, diferentemente da organização das escolas públicas brasileiras da época, uma das instituições que apoiavam as escolas japonesas da comunidade, que se chamava Nichigakuren (Confederação das Escolas de Língua Japonesa) ${ }^{1}$, tinha como filosofia "[...] jôsô-kyôiku (educação que valoriza a formação humanística, por meio de aulas que enfatizam a arte e a música com diversos instrumentos musicais) ou ningen-zukuri no kyôiku (educação que visa à formação do ser humano)" (MORALES, 2008, p. 58).

Tal filosofia educacional foi constatada no Regulamento da "Escola Modelo" (ESCOLA MODELO DE LÍNGUA JAPONESA DE DOURADOS, 1990), no item II do artigo $3^{\circ}$, da Especificidade da Instituição, e determina que a escola, por meio de aulas e cursos da cultura japonesa (cerimônia de chá, arranjo de flores, caligrafia, artes, artesanatos e música, etc.), vá incorporando estes aspectos e, portanto, oferecer o jôsô-kyôiku (educação emocional). Sendo assim, notamos uma grande influência das formações oferecidas pelas entidades de São Paulo no tocante às concepções tomadas pelas professoras, ao elaborar documentos, como também nas suas práticas do cotidiano.

Finalmente, podemos dizer que a "Escola Modelo" se consolidou como uma instituição que preconizou essa formação educativa moral e cultural, valorizando modos de comportamentos e formas de ser japonês aprendida e apropriada, a partir do ensino da língua, que os/as imigrantes japoneses/as trouxeram para Dourados e região. Um projeto gestado pelo fruto do seu desejo de aprender e preservar sua cultura original, que se configurou num espaço de referência para a comunidade nipônica e continua formando gerações de crianças da região, até os dias atuais, e contribuindo com a história da educação local e regional.

\footnotetext{
${ }^{1}$ Essa organização "[...] tinha como meta preservar e transmitir a língua e a cultura japonesa aos seus descendentes como língua de herança (LH), sendo liderada principalmente por professores e pais de alunos numa visão intergeracional e interna da comunidade" (MORALES, 2008, p. 93).
} 


\section{Educação informal e educação formal: a valorização da cultura nipo- brasileira}

Na discussão sobre a educação do grupo de descendentes de imigrantes japoneses no Brasil, é notado de que as famílias japonesas não poupam esforços para a formação escolar dos seus filhos que, consequentemente, alcançam o sucesso escolar e profissional. Setoguti (2008, p. 1172) afirma que "[...] este esforço incomensurável das famílias para fazer dos filhos pessoas educadas seja para ganhar respeitabilidade, seja para ascender socialmente - é a base do sucesso escolar dos nipo-brasileiros". Tal perspectiva é percebida na lembrança de infância da sra. Satoko, vivida no Japão - quando ela conta que recebeu grande incentivo para a leitura vindo da sua mãe -, e destacou a importância da educação para sua vida e de seu filho.

Então, não pensava desde o começo fazer isso (ensinar/ser professora). Eu não queria que o meu filho esquecesse a língua japonesa, e já que ele estava interessado... Eu tenho lembranças de infância, com a minha mãe que lia bastantes livros para mim. Naquele Hokkaido, tão atarefado Hokkaido, claro que quando estava muito atarefada, ela acabava dormindo de cansaço. Porém no inverno, na cama... ela lia para mim, e eu acabava dormindo sem saber... As crianças, naquele tempo, dormiam lá pelas 10 horas. No lugar dos cânticos infantis, ela sempre conversava, seja sobre a sua vida, ou diversas histórias (SATOKO, 2016).

Concordamos com Setoguti (2008, p. 1171) que, ao analisar os fatores culturais e motivacionais subjacentes à bem-sucedida trajetória escolar dos/as imigrantes japoneses/as, indica que a base do êxito "[...] está na herança cultural, fruto de uma experiência histórica promovida pelo Estado moderno japonês, em prol da educação". A história da universalização da educação que ocorreu no período Meiji (1868-1945), quando o Japão entrou no cenário econômico mundial visando à modernização do país, permitiu diversas mudanças, principalmente de cunho social, que colocou a educação nipônica como centro.

Ao analisarmos o surgimento da Escola Modelo Língua Japonesa de Dourados, notamos a especificidade no contexto étnico educacional da região, o qual, pelas entrevistas com as professoras pioneiras das escolas japonesas, a decisão de manter e continuar com as escolas foi das mulheres, as quais resistiram apontando a necessidade de propagar o ensino da língua. Com os relatos, avaliamos que "[...] as escolas japonesas na região douradense não surgem pela falta de oferta de escolas públicas locais, como aconteceu em outros contextos, mas foram sendo constituídas por desejo do grupo no sentido de preservar a língua e a cultura japonesa de seus antepassados" (KOCHI, 2017, p. 44). A partir da fala da sra. Satoko, tal espaço educativo surge a partir das relações da vizinhança da colônia, quando as mulheres, jovens esposas, buscavam momentos de descanso e lazer. Nessas conversas decidem deixar os filhos em sua casa, para que ela cuidasse e lhes ensinasse a língua japonesa. 
Pediam para brincar juntos (as crianças). E as senhoras e suas amigas ficavam conversando e tomando chá. E eu ficava no quarto ao lado, lia livros para elas, e cantos, naquela época compramos um tocador. [...] Ensinava os cantos, todos aprendiam e cantávamos (SATOKO, 2016).

Foi sendo constituído, por uma opção pessoal de cada professora que iniciou as atividades por conta própria, como em outro fragmento no relato da entrevistada sra. Yasuko, ela conta que começou a ministrar aulas nos anos finais da década de 1970, quando morou próximo de Dourados.

[...] morava em Fátima. Uns três anos antes, havia escola de língua japonesa de Fátima. Antes tinha... [...] Não havia outra pessoa (para continuar), e acabou fechando. [...] E, em Fátima havia duas senhoras do Paraná. Uma se chamava sra. Yamamoto, e outra sra. Taeko. Essas duas mulheres conversaram e decidiram reabrir a escola japonesa, aconteceu isso (YASUKO, 2016).

Conforme Setoguti (2008), as escolas surgem no seio da responsabilidade grupal, que concebe a educação escolar das gerações seguintes como um projeto coletivo, superando o simples interesse pessoal de cada família. A mobilização grupal da comunidade possibilitou a educação dos seus descendentes e na região de Dourados não foi diferente. Destacamos a atuação da mulher nestes espaços imprescindíveis para os imigrantes (associação e escola) e sua organização comunitária. Com a participação ativa, elas foram "[...] oficialmente, as verdadeiras 'peças de manutenção e resistência' dessas tradições na cidade" (KUBOTA, 2008, p. 76).

Sobre a ênfase da língua japonesa, a maioria dos entrevistados conta que se esforçou para ensinar a língua e incentivou os netos a aprenderem também, como parte dos valores instituídos da família. Destacamos que, para os japoneses a habilidade de falar a língua mais do que uma ferramenta de comunicação, propicia apreensão do universo cultural e moral nipônicos.

Entre os imigrantes é notável a crença de que a aquisição da língua japonesa equivale a ipso facto à aquisição do "espírito japonês", ou seja, os preceitos morais peculiares à cultura japonesa. É corrente a expressão como "aquele menino é honesto porque sabe falar o japonês" ou "veja que a moça é preguiçosa porque ela não sabe falar o japonês" (IZUMI, 1972, p. 376).

O fato de falarem ou não o idioma, para os japoneses, demonstra a marca da diferença, da pertença ao grupo e parte da socialização de suas normas grupais. Os entrevistados confirmam:

Os meus filhos, eles saíram pra fazer ensino superior, os três tem o nihongo nouryoku shiken [prova de proficiência em língua japonesa], a filha mais velha tem o segundo nível, os outros também tem o primeiro nível, eles falam bastante a língua japonesa. Então, eu quero passar os valores, a cultura, e a parte 
boa do Japão, e queria que seguisse pros netos. Penso que se meus filhos falam bem o nihongo [língua japonesa], os netos também vão falar. É... então, se eu ensinei isso pros filhos, então os netos também são ensinados. Depois também fazem Kumon, japonês, inglês, português. Por que que quero que meus filhos aprendam a língua japonesa? Porque muitos valores não têm como passar em língua portuguesa. Os valores da cultura japonesa são duros pra traduzir. Aprender a língua é parte dos valores, da cultura também. Eu acredito que como eu passei pros filhos, acho que passa sim pros netos (TANIGUCHI, 2015).

Ah realmente, quando se fala em japonês... porque eu não entendo muito português, então, se eles aprendesse nihongo [japonês] daria pra conversar, ter comunicação com eles. Né? Por isso se eles aprendessem o japonês eu ficava contente (NAKANO, 2015).

Por alguns valores serem difíceis de traduzir para o português, acreditam que, de certa forma, para serem compreendidos, tanto pelos filhos, quanto pelos netos, o idioma é necessário para manter a comunicação e o espírito japonês. Assim como o senhor Taniguchi, o senhor Nakano também relatou orgulhosamente sobre a participação de uma de suas filhas no concurso de oratória benrontaikai, organizado com a disputa entre todos os estados brasileiros. Como prêmio recebeu uma passagem de ida e volta para o Japão, adquirindo, posteriormente, um emprego estável no país. Descrevem, com entusiasmo, as conquistas e cursos que os filhos realizaram na aprendizagem da língua e depositam certa expectativa para que o mesmo aconteça com os netos.

Em outras palavras, a língua, enquanto mecanismo da balança de poder presente em qualquer configuração social, atua na distinção entre os falantes e não falantes do idioma, incutindo o sentimento de isolamento e solidão dos que não dominam o dialeto, no caso a língua portuguesa da grande maioria entre os brasileiros e os poucos falantes da língua japonesa no caso dos imigrantes. Nas palavras de Gebara (2005, p. 25), "os grupos estabelecidos consideram-se sempre mais cultos, mais civilizados, mais decentes, mais respeitáveis". No ponto de vista do autor, grupos estabelecidos compartilham uma história comum (memórias, parentescos, rituais), padrões adotados normalmente distintos dos forasteiros que colocam em risco seus valores e posições na vida comunitária. Alguns dos imigrantes afirmam não saber muito, até hoje, sobre a língua dos brasileiros, mas ao mesmo tempo se esforçam para consolidar um diálogo e se orgulham de manter sua língua materna e os princípios da cultura nipônica. Assim, relata o Sr. Taniguchi:

Bom, eu acredito que o pai é o espelho da criança. Então sempre precisa batalhar e não ter vergonha se o filho virar as costas e você também, não ter vergonha do passado do que você fez. Por isso o que eu penso, que se eu der conta da minha vivência, o resto, é importante também ajudar os outros. Então eu acredito assim que seguindo esse caminho as crianças também vão crescendo olhando essas atitudes (TANIGUCHI, 2015). 
As autorregulações provenientes das coações realizadas pelos pais eram reafirmadas fora do lar quando a pessoa agia fora dos padrões exigidos pelo seu grupo social resultava na estigmatização de sua conduta. Por isso, procuravam fazer as "coisas certas" para não serem excluídos, uma vez que "a punição pelo desvio do grupo ou, às vezes, até pela suspeita de desvio, é perda do poder, acompanhada de rebaixamento do status. [...] A auto-imagem e auto-estima de um indivíduo estão ligadas ao que os outros membros do grupo pensam dele" (ELIAS; SCOTSON, 2000, p. 40). Mais do que isso, depois de internalizado certas convenções de comportamento, como forma de "segunda natureza", muitas vezes o que o japonês pensa de si mesmo, pesa em grande medida, culpandose em determinadas situações. Assim, certos valores eram enfatizados:

Ah isso sempre... Pai e mãe, isso realmente era falado... tem que fazer o certo... os valores realmente eram exigidos né... [...] Eu tinha medo dos pais [risos] [...] Porque... tinha que respeitar. Eram exigentes também, mas, como fala, a educação... a gente pensava que os pais eram severos. Não... não é que tem que respeitar, mas eu acho que precisava [educação/severos] pra respeitar, eu achava... os pais realmente na educação eram duros... (NAKANO, 2015).

Então, mesmo na escola, os colegas que são de um ou dois anos pra cima, os mais velhos que a gente, no caso os veteranos, já tem que falar de outra maneira, mostrando respeito, e a mesma coisa na sociedade também, se falar com uma pessoa mais velha, já se tem que ter cuidado, jeito de se falar, tem que respeitar e com o pai e mãe também tem que falar de forma diferente. Com os da mesma idade pode conversar normalmente, mas os de um ou dois anos mais velhos tem que tomar cuidado na hora de falar, da mesma forma com os pais, isso foi ensinado (TANIGUCHI, 2015).

Valores como não roubar, não mentir e não fazer mal ao outro ou o incomodar, constituía-se como costume fundamental. Para Sakurai (2014, p. 286), cooperar com o outro significa "dividir, solidarizar-se, ensinar e aprender, decidir, apontar caminhos, julgar, entre outras tantas atribuições". Os interesses do grupo têm preferência sobre os interesses individuais, caso não pensem dessa forma, são vistos como negligentes. Percebe-se que a coletividade, o controle, o autocontrole, a vergonha e a disciplina estavam sempre presentes na formação do caráter e, consequentemente, na educação prevista da comunidade nipo-brasileira.

\section{Considerações finais}

A nossa investigação se iniciou com as fontes documentais encontrados no acervo da Escola Modelo de Língua Japonesa e da Associação Cultural NipoBrasileiro de Dourados-MS. Inicialmente tais documentos sugeriram nomes de pessoas para identificação de personalidades na investigação sobre a educação da imigração japonesa e seus descendentes na região de Dourados. Além dos 
documentos, as entrevistas nos deram pistas da organização da comunidade, apontando as mudanças sociais que ocorreram no tempo e espaço, evidenciando as especificidades regionais e locais das/os imigrantes que vieram e ficaram na região Centro-Oeste do país.

Os valores familiares da educação informal, reforçados na escola de uma educação formal, consolidou um habitus aos indivíduos nessa figuração nipobrasileira, fundamental para a permanência do grupo na região estudada. Imersos nesse processo, no caso dos/das imigrantes japoneses/as, entendemos que eles/elas mesmos/as acabaram regulando e autorregulando o comportamento, fazendo com que essa transmissão educacional fosse de modo imperceptível, enquanto "segunda natureza". O habitus foi sendo passado de geração em geração, por estarem eles/as mesmos/as envolvidos/as nesse processo civilizador e que, apesar de ter suas permanências e rupturas intergeracionais e interculturais, vão se naturalizado dentro das práticas cotidianas, controladas e autocontroladas dentro das normas sociais implícitas do ser nipo-brasileiro.

Além de demonstrarem o sucesso obtido pela escolha de terem vindo ao Brasil, evidenciam a persistência nipônica fundamental à formação de sua personalidade, empreendendo na força do trabalho árduo, o termo gambaru (persistir) em sua educação. Suportar com paciência, a expressão é frequentemente invocada pelos pais, professores e colegas, na superação dos esforços (IWAMOTO, 2016). Igualmente, White (1988, p. 56) explicita que "no Japão, continuar avançando, persistir, não desistir são em si importantes e mostram mais uma vez que o significado do modo como uma coisa é feita é mais importante que o fim alcançado". Mais do que sofrimento e dificuldades transpassados, a autodisciplina e a dedicação empreendidos na jornada, resultam na conquista e no sucesso de viver em um país totalmente diferente do mundo conservado em suas memórias.

Para a escrita da história da imigração japonesa local, da história de grupos étnicos e, principalmente, a escrita da história da educação da região CentroOeste, consideramos esta investigação como pertinente e apropriada ao nosso momento social e político. Esperamos ter contribuído, também, para a imigração japonesa no Brasil, história educação de Mato Grosso do Sul, mais especificamente da região douradense, apontando um dos vieses investigativos do grupo étnico específico, que contribui com a formação dessa cidade de muitos povos, almejando abrir outras portas para pesquisas sobre a comunidade nipobrasileira de Dourados e do Brasil.

\section{REFERÊNCIAS}

ALBERTI, Verena. Histórias dentro da história. In: PINSKY, Carla Bassanezi (org.) Fontes históricas. 2. ed. São Paulo: Contexto, 2008.

BENEDICT, Ruth. O crisântemo e a espada: padrões da cultura japonesa. São Paulo: Perspectiva, 1972. 
BRANDÃO, Carlos da Fonseca. Norbert Elias: formação, educação e emoções no processo de civilização. Petrópolis: Vozes, 2003.

BRASIL. Decreto-Lei no 406, de 4 de Maio de 1938. Dispõe sobre a entrada de estrangeiros no território nacional. Disponível em:

https://www2.camara.leg.br Acesso em: 27 maio 2021.

CAMACHO, Luiza. M. Y. Japanese Cultural Values Present in the education of nipo-brazilian. In: KISHIMOTO, Tizuko Morchida; DEMARTINI, Zeila de Brito Fabri. (orgs.) Education and culture: Brazil and Japan. São Paulo: USP, 2012.

DEMARTINI, Zeila de Brito Fabri. Imigração e educação: discutindo algumas pistas de pesquisa. Pro-Posições. v. 15, n. 3 (45), p. 215-228, set.-dez., 2004.

DEMARTINI, Zeila de Brito Fabri. Relatos orais de famílias de imigrantes japoneses: elementos para a história da educação brasileira. Educação \& Sociedade. Ano XXI, n. 72, p. 43-72, ago.2000.

ELIAS, Norbert. A sociedade dos indivíduos. Org. por Michael Schöter. Tradução Vera Ribeiro. Rio de Janeiro: Jorge Zahar, 1994.

ELIAS, Norbert. Introdução à sociologia. Tradução Maria Luisa Ribeiro Ferreira. 4. ed. São Paulo: Edições 70, 2014.

ELIAS, Norbert. O processo civilizador: formação do Estado e civilização. v.

2. Rio de Janeiro: Zahar, 1993.

ELIAS, Norbert. O processo civilizador: uma história dos costumes. 2. ed. v. 1. Rio de Janeiro: Zahar, 2011.

ELIAS, Norbert; SCOTSON, John. L. Os estabelecidos e outsiders: sociologia das relações de poder a partir de uma pequena comunidade. Rio de Janeiro: Zahar, 2000.

ESCOLA MODELO DE LÍNGUA JAPONESA DE DOURADOS. Documento da Fundação da Escola Modelo de Língua Japonesa de Dourados, 1990.

GEBARA, Ademir. Conversas sobre Norbert Elias: depoimentos para uma história do pensamento sociológico. Piracicaba: Biscalchin Editor, 2005.

GEBARA, Ademir.; SARAT, Magda. Infância e educação nas obras de Erasmo de Roterdã e Norbert Elias. In: SARAT, M. (org.) Fundamentos filosóficos da educação infantil. Maringá: Eduem, 2009. 
GOUDSBLOM, Johan. A vergonha: uma dor social. In: GEBARA, Ademir.; WOUTERS, Cas. (orgs.) O controle das emoções. João Pessoa: Editora Universitária da UFPB, 2009.

HANDA, Tomoo. O Imigrante Japonês. História de sua vida no Brasil. São Paulo: T. A. Queiroz Editor, Centro de Estudos Nipo-Brasileiros, 1987.

INAGAKI, Edna Mitsue. Imigração japonesa para o Brasil: os japoneses em Dourados, (Século XIX e XX). Dourados: Editora UEMS, 2008.

IWAMOTO, Vivian. Educação e civilidade nas memórias de infância de imigrantes japoneses. 145f. Dissertação (Mestrado em Educação). Universidade Federal da Grande Dourados (UFGD), Dourados-MS, 2016.

IZUMI, Seiichi. A estrutura psicológica da colônia japonesa no Brasil. Petrópolis: Vozes, 1972.

KISHIMOTO, Tizuko Morchida. A educação infantil no Japão. Cadernos Cedes, v. 37, p. 23-44, 1995.

KOCHI, Joice Camila dos Santos. "Escola Modelo de Língua Japonesa de Dourados-MS": movimentos, histórias e memórias de mulheres. 109f. Dissertação (Mestrado em Educação). Universidade Federal da Grande Dourados (UFGD), Dourados-MS, 2017.

KUBOTA, Nádia Fujiko Luna. Bon Odori e sobá: as obassan na transmissão das tradições japonesas em Campo Grande-MS. 2008. 210f. Dissertação (Mestrado em Ciências Sociais), Universidade Estatual Paulista - UNESP, Marília, SP, 2008.

MEIHY, José Carlos Sebe B. Manual de história oral. São Paulo: Loyola, 1996.

MORALES, Leiko Matsubara. Cem anos de imigração japonesa no Brasil: o japonês como língua estrangeira. 2008. 326f. Tese (Doutorado em Linguística), Universidade de São Paulo, São Paulo, 2008.

NASCIMENTO, Maria Leticia Barros Pedroso. Reconhecimento da sociologia da infância como área de conhecimento e campo de pesquisa, algumas considerações. In: FARIA, Ana Lúcia Goulart de; FINCO, Daniela. (orgs.) Sociologia da infância no Brasil. Campinas-SP: Autores Associados, 2011.

OCADA, Fábio Kazuo. Memories of the Japanese immigration in Brazil: an analysis of the values present at the nipo-brazilian identity. In: KISHIMOTO, Tizuko Morchida; DEMARTINI, Zeila de Brito Fabri. (orgs.) Education and culture: Brazil and Japan. São Paulo: USP, 2012. 
POLLAK, Michael. Memória, esquecimento, silêncio. Estudos Históricos. v. 2, n. 3, p. 3-15, Rio de Janeiro, 1989.

PORTELLI, Alessandro. Tentando aprender um pouquinho: algumas reflexões sobre ética na História Oral. In: Projeto história: Revista do Programa de Estudos Pós-graduados em História do Departamento de História da PUC-SP (Pontifícia Universidade Católica de São Paulo). São Paulo, n. 15, p. 13-49, abr. 1997.

SAKURAI, Célia. Imigração japonesa para o Brasil: um exemplo de imigração tutelada (1908-1941). In: FAUSTO, Boris. (org.) Fazer América. 2. ed. São Paulo: Editora da Universidade de São Paulo, 2000.

SAKURAI, Célia. Os japoneses. 2. ed. São Paulo: Contexto, 2014.

SETOGUTI, Ruth Izumi. A tradição educacional entre os imigrantes japoneses e os nipo-brasileiros. In: VIII CONGRESSO NACIONAL DE EDUCAÇÃO da PUCPR (EDUCERE) e III CONGRESSO IBERO-AMERICANO SOBRE VIOLÊNCIA NAS ESCOLAS (CIAVE). Anais... Curitiba-PR, 2008.

VÁRIOS AUTORES, Uma epopéia moderna: 80 anos da imigração japonesa no Brasil. São Paulo: HUCITEC/Sociedade Brasileira de Cultura Japonesa, 1992.

WAKISAKA, Katsunori. Michaelis: dicionário prático japonês-português. São Paulo: Aliança Cultural Brasil-Japão, 2003.

WHITE, Merry. Desafio Educacional Japonês: compromisso com a infância. São Paulo: Brasiliense, 1988.

Recebido em: 25 de fevereiro de 2021. Aceito em: 27 de maio de 2021. Publicado em: 30 de junho de 2021. 